\title{
RESEARCH ON THE INFLUENCE OF KNOWLEDGE BASE AND RELATIONSHIP NETWORK ON INNOVATION PERFORMANCE
}

\author{
Hui Wang, Xiaoming Zhang, Liren An \\ School of Economics \& Management, Northwest University,710127, Shaanxi xi'an, China \\ *Corresponding Author Email: 165253617@qq.com
}

This is an open access article distributed under the Creative Commons Attribution License, which permits unrestricted use, distribution, and reproduction in any medium, provided the original work is properly cited.

\begin{tabular}{ll}
\hline ARTICLE DETAILS & ABSTRACT \\
\cline { 3 - 3 } Article History: & $\begin{array}{l}\text { This paper combines enterprise knowledge base and relational network to study its impact on innovation } \\
\text { performance. It analyzes how the combination of knowledge base width, knowledge base depth, relationship } \\
\text { network width and relationship network depth influence on the innovation performance of enterprises. The } \\
\text { empirical results show that relationship network and knowledge base have a positive impact on innovation } \\
\text { Received 7 November 2017 } \\
\text { Accepted 10 December 2017 } \\
\text { Available online 5 January 2018 }\end{array}$ \\
on innovation performance, and "deep network-wide knowledge" and "wide network-deep knowledge" have a \\
positive impact on innovation performance.
\end{tabular}

KEYWORDS

Knowledge Base, Relationship Network, Innovation Performance

\section{BACKGROUND OF THE STUDY}

With economic globalization, the speed of information update is faster, and the operating environment is more and more unstable. In addition to the impact of R \& D capability, knowledge diversity and other factors, the innovation performance of enterprises is closely related to the resources that can be used by enterprises, including two key elements, namely relationship network and knowledge base. Through relationship network can help management to obtain information and knowledge to provide new directions and ideas for innovation. Of course, knowledge base is whether managers can identify external opportunities and accurately grasp the fundamental of market opportunities. The influence of relationship network and knowledge base of enterprise executives on enterprise innovation performance has attracted the attention of researchers. A researcher proved that the network can help to transfer information between enterprises, and promote the innovation of the decision, and then promote the innovation performance [1]. From the perspective of diversity, another researcher discussed the effectiveness of knowledge base in the development of innovative decision-making advantages [2]. Only by paying attention to innovation and investment, can innovation performance be realized. Nevertheless, most mathematician's separate relationship network from knowledge base, and discuss the role of the two. In fact, these two factors are not independent effects.

According to the social network theory, the heterogeneous network can bring the external knowledge and information to the subject. According to the absorptive capacity theory, the internal knowledge base needs to absorb and transform the information and knowledge obtained from relational network [3]. Therefore, it forms the different combination patterns of relationship network and knowledge-base. This paper tries to find out how relationship network and knowledge base affect the innovation performance.

\section{RELEVANT THEORETICAL BASIS}

Relationship network (network depth and network width) and knowledge base (knowledge depth and knowledge width) play a role in the process of influencing innovation performance. This paper identifies several models of the combination of relational networks and knowledge bases. That is, pure network model, pure knowledge base model, deep network-deep knowledge model, deep network-wide knowledge model, wide network-deep knowledge model and wide network -wide knowledge model. And analyzes its influence on innovation performance.

\subsection{The Influence of Relationship Networks on Innovation} Performance

Simply consider the relationship between enterprise network, enterprise relationship network enterprise breadth members play many other social roles such as company executives, industry association leaders, university professors, government officials, all club members, fraternities and alumni for the enterprise team to heterogeneous resources. This heterogeneous resource expands the information set of enterprises and has positive significance for innovation performance. The depth of enterprise relationship network shows the degree of Embeddedness and the quality of the relationship among the employees in the social network. This expands the opportunities for enterprises to obtain resources and speeds up the acquisition, which has a positive significance for innovation performance. Accordingly, this paper proposes hypothesis 1 (H1): enterprise relationship network has a positive impact on innovation performance.

\subsection{The Influence of Knowledge base on Innovation Performance}

The education level and rich career experience of enterprise members make up employees or diversified or professional knowledge. The breadth of the knowledge base, that is, the degree of diversification of knowledge, is conducive to the team to identify more opportunities, to examine and deal with complex problems from different perspectives, and to enhance the overall ability to solve problems [4]. So, the breadth of the staff's knowledge base helps companies to have more and more innovative ideas. The depth of the foundation of enterprise knowledge, due to the introduction of the government, industry associations or professional research institutions, has specialized in a particular field of knowledge and skills, which can help enterprise innovation is more profound and more professional judgment [5]. Accordingly, this paper proposes hypothesis 2 (H2): knowledge base has a positive impact on innovation performance. 
2.3 The Influence of "Deep Network-Deep Knowledge" on Innovation Performance

On the one hand, deep embedding in the external network can make the enterprise obtain the required information at a faster speed and less cost. But for a long time, it will lead to cognitive locking due to the inertia of these network members, leading to a high degree of convergence of economic forecasts, judgments and cognition. At the same time, the internal knowledge base is limited to a certain field, which hinders the access to diversified information. On the other hand, with deep knowledge, the firm's depth embedded in the external network will make its ability to be rigid in innovation and affect its rapid response to external changes. Because of the theory of absorptive capacity, the internal knowledge of enterprises is mainly to absorb and transform the information obtained from the outside. If the scope of the external information is relatively narrow, the internal depth of knowledge cannot be effectively transformed and utilized, resulting in innovative knowledge. Accordingly, this paper proposes hypothesis 3 (H3): "deep network-deep knowledge" model has a negative impact on innovation performance.

\subsection{The Influence of "Deep network-wide Knowledge" on} Innovation Performance

On the one hand, the diversity of knowledge enables enterprises to search for heterogeneous knowledge resources in the external network, and select the right person to enter the enterprise, so as to obtain information related to decision-making, and ultimately promote the emergence of innovation. At this point, the depth embedded in the external network allows the enterprise to approach the appropriate director at a faster pace and less cost. On the other hand, the collision between diverse knowledge contributes to innovation. At this point, if the depth is embedded in the external network, the enterprise can acquire external knowledge at a faster pace, and further integrate with the internal diversification of knowledge, thereby increasing the possibility of innovation. Accordingly, this paper proposes Hypothesis 4 (H4): "deep network-wide knowledge" model has a positive impact on innovation performance.

\subsection{The Influence of "Wide Network-Deep Knowledge" on Innovation Performance}

According to the theory of absorptive capacity, the emergence of new knowledge requires innovative subjects to identify valuable new information, evaluate, digest, and apply it to new areas. Therefore, the deep knowledge base within the enterprise can identify the useful information from the external network diversification information, avoid excessive information and get bogged down in the "information quagmire"". At the same time, the deep knowledge base can integrate the external and diverse knowledge into the existing knowledge warehouse and combine it with the existing deep knowledge base to produce new knowledge to promote innovation. Accordingly, this paper proposes Hypothesis5(H5): "wide network-deep knowledge" model has a positive impact on innovation performance.

\subsection{The Influence of "Wide Network-Wide Knowledge" on Innovation Performance}

In the process of innovation, from the inside, enterprises must improve the ability of monitoring, assessing, absorbing and using knowledge, namely absorptive capacity. The breadth of knowledge within an enterprise affects the acquisition of its absorptive capacity. From the external point of view, enterprises share some common language with other enterprises in the external network to promote information access. However, according to a researcher, there is a lack of shared language between the diversified knowledge and the external diversification information within the enterprise [4]. Therefore, the diversity of knowledge within the enterprise hinders the process of transforming the diversified information obtained from the external network into new knowledge that contributes to the innovation performance through absorptive capacity. Accordingly, this paper proposes Hypothesis 6 (H6): "wide network-wide knowledge" model has a negative impact on innovation performance. The specific conceptual model is illustrated in figure 1.

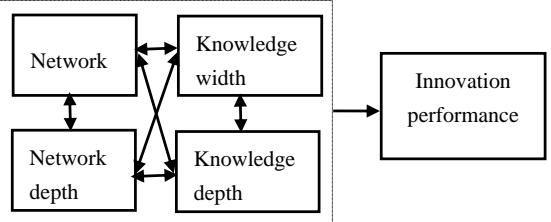

Figure 1: Conceptual model

\section{RESEARCH DESIGN}

\subsection{Variable Measure}

This study involves three variables: relationship network, knowledge base, and innovation performance. Both cited and cited classical literature with higher frequency of citation. The LIKERT-7-point method was used to measure the variables, and the respondents made 1-7 points according to the consistency of each item and the actual situation of the enterprise.

\subsection{Data Collection}

This study investigated the use of on-site interviews and e-mail transmission. A total of 220 enterprises were surveyed, and 201 samples were collected. The questionnaires were incomplete, and no partners were formed, and 192 samples were available. The questionnaire was filled with the CEO of the enterprise or the senior managers of other enterprises designated by it. They know more about the external network resources of the enterprise, and they are familiar with the knowledge base of the personnel of the enterprise.

\subsection{Reliability and Validity}

Cronbach 's Alpha system value and SPSS19.0 software is used to test reliability. The results are shown in table 1 . Network width, network depth, knowledge width, knowledge depth and innovation performance of Cronbach 's Alpha coefficients were 0.908, 0.912, 0.905, 0.901, 0.909. Cronbach's Alpha of all the variable coefficient was more than 0.7 and the scale has high internal consistency and stability. In terms of validity, the scale was designed based on the maturity scale of research in this field at home and abroad. The pre-test stage asked the executives and experts to evaluate and revise the scale, and the guarantee scale had higher content validity. Construction validity was tested by CFA method and AMOS20.0 software, and the results were shown in table 1.

The standardized coefficient of each measurement index was greater than 0.8 , and all reached 0.001 significant level. The combination reliability of each variable was greater than 0.9 , and the AVE was greater than 0.7, indicating that all the measurement items converged on each corresponding surface, and had higher convergence validity. Based on the CFA method, the discriminant validity test is shown in Table 1 and Table 2. The root mean square (AVE) of any latent variable is greater than the correlation coefficient with its latent variable, which indicates that the discriminant validity of each variable is good.

Table 1: Reliability and Validity Test

\begin{tabular}{|c|c|c|c|c|}
\hline Latent variable & Cronbachs' alpha & Standardized coefficient & Composite reliability & AVE \\
\hline \multirow{4}{*}{$\begin{array}{c}\text { Deep network } \\
\text {-deep knowledge }\end{array}$} & \multirow{4}{*}{0.908} & $0.807 * * *$ & \multirow{4}{*}{0.906} & \multirow{4}{*}{0.753} \\
\hline & & $0.812^{* * * *}$ & & \\
\hline & & $0.868 * * *$ & & \\
\hline & & $0.889^{* * * *}$ & & \\
\hline \multirow{4}{*}{$\begin{array}{c}\text { Deep network } \\
\text {-wide knowledge }\end{array}$} & \multirow{4}{*}{0.905} & $0.850^{* * * *}$ & \multirow{4}{*}{0.901} & \multirow{4}{*}{0.725} \\
\hline & & $0.798 * * *$ & & \\
\hline & & $0.911^{* * * *}$ & & \\
\hline & & $0.856^{* * * *}$ & & \\
\hline \multirow{4}{*}{$\begin{array}{l}\text { Wide network } \\
\text {-deep knowledge }\end{array}$} & \multirow{4}{*}{0.901} & $0.818^{* * * *}$ & \multirow{4}{*}{0.899} & \multirow{4}{*}{0.700} \\
\hline & & $0.897 * * *$ & & \\
\hline & & $0.862^{* * * *}$ & & \\
\hline & & $0.854^{* * * *}$ & & \\
\hline \multirow{4}{*}{$\begin{array}{c}\text { Wide network } \\
\text {-wide knowledge }\end{array}$} & \multirow{4}{*}{0.909} & $0.832^{* * * *}$ & \multirow{4}{*}{0.903} & \multirow{4}{*}{0.710} \\
\hline & & $0.866^{* * * *}$ & & \\
\hline & & $0.835^{* * * *}$ & & \\
\hline & & $0.847^{* * * * *}$ & & \\
\hline \multirow{3}{*}{$\begin{array}{l}\text { Innovation } \\
\text { performance }\end{array}$} & \multirow{3}{*}{0.910} & $0.845^{* * * *}$ & \multirow{3}{*}{0.915} & \multirow{3}{*}{0.741} \\
\hline & & $0.891^{* * * *}$ & & \\
\hline & & $0.822^{* * * *}$ & & \\
\hline
\end{tabular}

Table 2: Correlation Coefficient of Measurement Variables

\begin{tabular}{|c|c|c|c|c|c|c|c|}
\hline Variable & Mean value & $\begin{array}{c}\text { Standard } \\
\text { deviation }\end{array}$ & 1 & 2 & 3 & 4 & 5 \\
\hline $\begin{array}{c}\text { 1 Deep network } \\
\text {-deep knowledge }\end{array}$ & 5.26 & 1.30 & 1 & & & & \\
\hline $\begin{array}{c}\text { 2 Deep network } \\
\text {-wide knowledge }\end{array}$ & 4.96 & 1.23 & $0.782^{* * *}$ & 1 & & & \\
\hline $\begin{array}{c}3 \text { Wide network } \\
\text {-deep knowledge }\end{array}$ & 5.07 & 1.11 & $0.689 * *$ & $0.667 * *$ & 1 & & \\
\hline $\begin{array}{c}4 \text { Wide network } \\
\text {-wide knowledge }\end{array}$ & 5.23 & 1.15 & $0.496 * *$ & $0.577^{* *}$ & $0.681^{* *}$ & 1 & \\
\hline $\begin{array}{c}5 \text { Innovation } \\
\text { performance }\end{array}$ & 4.79 & 1.05 & $-0.482 * *$ & $0.554^{* *}$ & $0.589 * *$ & $-0.577^{* *}$ & 1 \\
\hline
\end{tabular}


From the above table, we can see that the relationship among variables is verified. It is assumed that $\mathrm{HI}, \mathrm{H} 2, \mathrm{H} 4, \mathrm{H} 5$ are positive correlation, and $\mathrm{H} 3$ and $\mathrm{H} 6$ are negative correlation. All of the above hypotheses are validated.

\section{CONCLUSION}

Through exploring the depth and width of enterprise knowledge base, and the depth and width of enterprise relationship network, the impact on enterprise knowledge innovation is explored. The main conclusions are as follows: "deep network wide knowledge" and "wide network deep knowledge" have a positive impact on innovation performance. The deeper the enterprise knowledge base is, the wider the relationship network is, the higher degree of correlation between the knowledge of the enterprise, and the knowledge that can be drawn from the outside, and the higher the innovation performance of the enterprise. Knowledge base diversification, if you can embed the network to absorb the core related knowledge, for the improvement of enterprise innovation performance is of great benefit. With the increase of the non-related diversity of technological knowledge base, the more involved the new technological knowledge field, the more possibility of the combination of new knowledge elements, and the more conducive to enterprise innovation. It is found that deep network deep knowledge and wide network wide knowledge have a negative impact on innovation performance. This is probably because if the enterprise network breadth is wide, it means that the enterprise $\mathrm{R} \& \mathrm{D}$ personnel have heterogeneous cognition, and hold different views on specific issues, and it is difficult to form consensus on the new knowledge combination. If the non-knowledge related diversification of the enterprise knowledge base is high, it is likely to further increase the difficulty of the new knowledge combination. Therefore, although the diversity of knowledge base brings the potential of new knowledge combination, the high cognitive difference between divergent knowledge structure and enterprise R \& D personnel makes it difficult to realize the potential of new knowledge combination.

\section{REFERENCES}

[1] Wincent, J., Anokhin, S., Ortqvist, D. 2010. Does network board capital matter? A study of innovative performance in strategic SME networks. Journal of Business Research, 63 (3), 265- 275.

[2] Tang, Q.Q., Luo, D.L. 2009. Political relations, social capital and policy resource acquisition. World economy, (7), 87-100.

[3] Florida, R., Ushing, C.R., Gates, G. 2002. When social capital stifles innovation. Harvard Business Review, 80 (8), 20.

[4] Fang, E., Tang, Y. 2012. The Effects of Knowledge and Network Assets Alignment on Open Innovation Success: The Exploration of Open Source Software (OSS) Development. Winter Marketing Educators' Conference, Florida.

[5] Nesta, L, Saviotti, P.P. 2005 Coherence of the knowledge base and the firm's innovative performance: Evidence from the US pharmaceutical industry. Journal of Industrial Economics, 53 (1), 123-142. 